\title{
Circumvention of multi-drug resistance of cancer cells by Chinese herbal medicines
}

Stella Chai ${ }^{1}$, Kenneth KW To², Ge Lin ${ }^{1 *}$

\begin{abstract}
Multi-drug resistance (MDR) of cancer cells severely limits therapeutic outcomes. A proposed mechanism for MDR involves the efflux of anti-cancer drugs from cancer cells, primarily mediated by ATP-binding cassette (ABC) membrane transporters including P-glycoprotein. This article reviews the recent progress of using active ingredients, extracts and formulae from Chinese medicine $(C M)$ in circumventing $A B C$ transporters-mediated MDR. Among the $A B C$ transporters, Pgp is the most extensively studied for its role in MDR reversal effects. While other MDR reversal mechanisms remain unclear, Pgp inhibition is a criterion for further mechanistic study. More mechanistic studies are needed to fully establish the pharmacological effects of potential MDR reversing agents.
\end{abstract}

\section{Review}

Multi-drug resistance (MDR)

Multi-drug resistance (MDR) in cancer chemotherapy refers to the ability of cancer cells to survive from treatment of a wide range of drugs [1]. In addition to the MDR induced by drugs in early exposure, the MDR cancer cells may subsequently develop cross-resistance to several unexposed and structurally unrelated chemotherapeutic agents [2]. Mechanisms of MDR include decreased uptake of drugs, alterations in cellular pathways and increased active efflux of drugs [3-5] (Figure 1). Overexpression of ATP-binding cassette $(\mathrm{ABC})$ transporters is one of the most common mechanisms. ABC transporters are large membrane-bound proteins consisting of two nucleotide-binding domains (NBDs) and two transmembrane domains (TMDs) which mediate the active transport of substrate drugs out of the cell (Figure 2). Overexpression of the three major $\mathrm{ABC}$ transporters, i.e. P-glycoprotein (Pgp), multidrug-resistance-associated protein 1 (MRP1) and breast cancer resistance protein (BCRP/ABCG2) is frequently observed in cancer cell lines selected with chemotherapeutic drugs [6] and critical to clinical drug resistance [7].

\section{P-glycoprotein (Pgp)}

P-glycoprotein (Pgp) [8], which is also referred to as $A B C B 1$ and MDR1, is the most studied ABC transporter. Pgp transports a wide range of chemotherapeutic

\footnotetext{
* Correspondence: linge@cuhk.edu.hk

${ }^{1}$ School of Biomedical Sciences, Faculty of Medicine, The Chinese University of Hong Kong, Shatin, Hong Kong SAR, China
}

agents including the anthracyclines, vincas, taxanes, etoposide and mitoxantrone [6]. Pgp is expressed in various tissues in the body. Remarkably high expression can be found in endothelial cells of capillary blood vessels in the brain as well as other organs including intestines, testes and skin $[9,10]$. Pgp expression is often detected in renal carcinoma, colon carcinoma, adrenal carcinoma and teratocarcinoma [9]. Substrate drugs can bind to Pgp through multiple binding sites, thereby allowing flexibility in the mechanism of transport $[11,12]$.

\section{Multidrug-resistance-associated protein 1 (MRP1)}

The second major MDR transporter, multidrug-resistance-associated protein (MRP), was first discovered in a doxorubicin-selected lung cancer cell line [13]. A member of the ABCC subfamily, MRP1 is encoded by the $A B C C 1$ gene [14]. Physiologically, MRP1 tends to pump drugs into the body, rather than excreting them into the bile, urine or gut $[15,16]$. MRP1 was highly expressed in skeletal muscles [17]. Overexpression of MRP1 is in cancer types such as lung, colon and various forms of leukaemia [18].

\section{Breast cancer resistance protein (BCRP/ABCG2)}

Recently, ABCG2 was identified in cancer cell lines selected with mitoxantrone that do not express Pgp and MRP1. As ABCG2 was simultaneously discovered by several research groups, it was also named $B C R P, A B C P$ and MXR [19-21]. ABCG2 is expressed in a range of tissues, most abundantly in the liver and intestinal epithelia [22,23]. ABCG2 is localized in the apical region in
C Biomed Central

C 2010 Chai et al; licensee BioMed Central Ltd. This is an Open Access article distributed under the terms of the Creative Commons Attribution License (http://creativecommons.org/licenses/by/2.0), which permits unrestricted use, distribution, and reproduction in any medium, provided the original work is properly cited. 


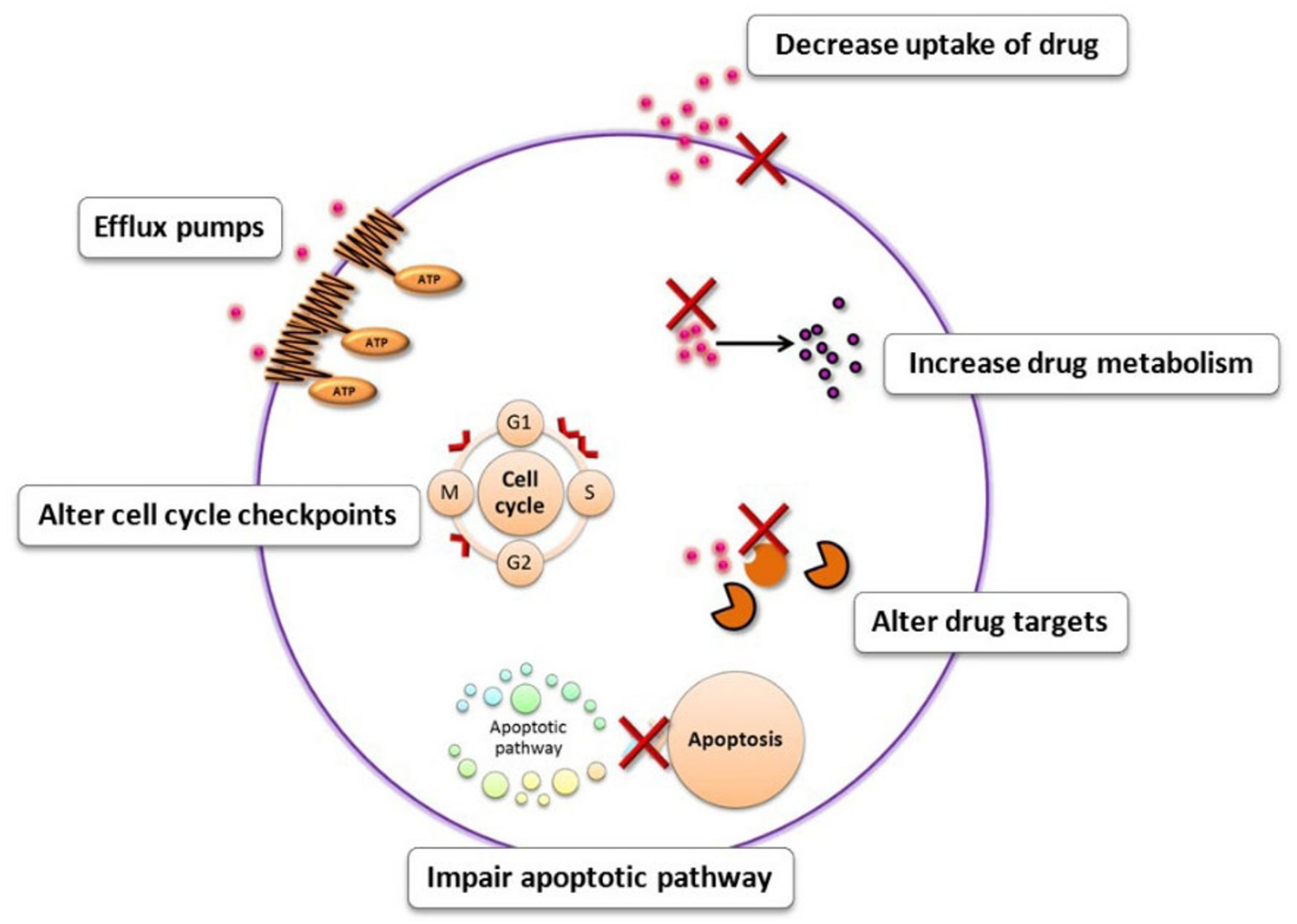

Figure 1 Mechanisms of MDR towards cancer chemotherapeutic drugs. Cancer cells can develop resistance to multiple drugs by various mechanisms as depicted. Mechanisms include (a) decreased uptake of drug, (b) reduced intracellular drug concentration by efflux pumps, (c) altered cell cycle checkpoints, (d) altered drug targets, (e) increased metabolism of drug and (f) induced emergency response genes to impair apoptotic pathway.

cells [24] and transports many cytotoxic drugs, detoxified metabolites, toxins and carcinogens [25].

\section{Chinese medicine and MDR}

How to tackle the MDR cells in chemotherapy is a pressing issue in cancer treatments. Verapamil was the first known Pgp inhibitor to increase the intracellular concentration of anticancer agents in MDR cells by binding to Pgp and inhibiting the Pgp-mediated efflux [26]. It was believed that anticancer drug resistance could be reversed by drug efflux inhibition. Researchers developed and tested a range of Pgp inhibitors to improve the pharmacological effects of chemotherapy in cancer patients [27-29]. However, none of these Pgp inhibitors was further developed for clinical use. Many researchers are looking into Chinese medicine $(\mathrm{CM})$ for potential MDR reversing agents.

This article reviews some of the recent findings on the circumvention of ABC transporters-mediated MDR by various ingredients and extracts of $C M$ and their formulae based on whether the MDR reversal involved Pgp alteration.

\section{MDR reversal involving Pgp inhibition Active ingredients - alkaloids}

Tetrandrine, a calcium channel blocker, is a bisbenzylisoquinoline alkaloid isolated from the root of Stephania tetrandra (Fenfangji) [30]. Tetrandrine reversed MDR in vitro and modulated Pgp-mediated drug efflux [30-33]. A combination of tetrandrine with doxorubicin or vincristine in vitro demonstrated synergistic anticancer effects [34]. Tetrandrine reduced Pgp expression [35]. In mice bearing resistant MCF-1/DOX cells, tetrandrine potentiated the antitumor activities of doxorubicin without significantly increasing toxicity [36]. A synthetic halogenated form of tetrandrine increased vinblastine accumulation in a dose-dependent manner in resistant P388/DOX cell line and prolonged the life-span of tumour-bearing mice up to $25 \%$ without any side effects [37]. In a recent clinical trial, a combination of 


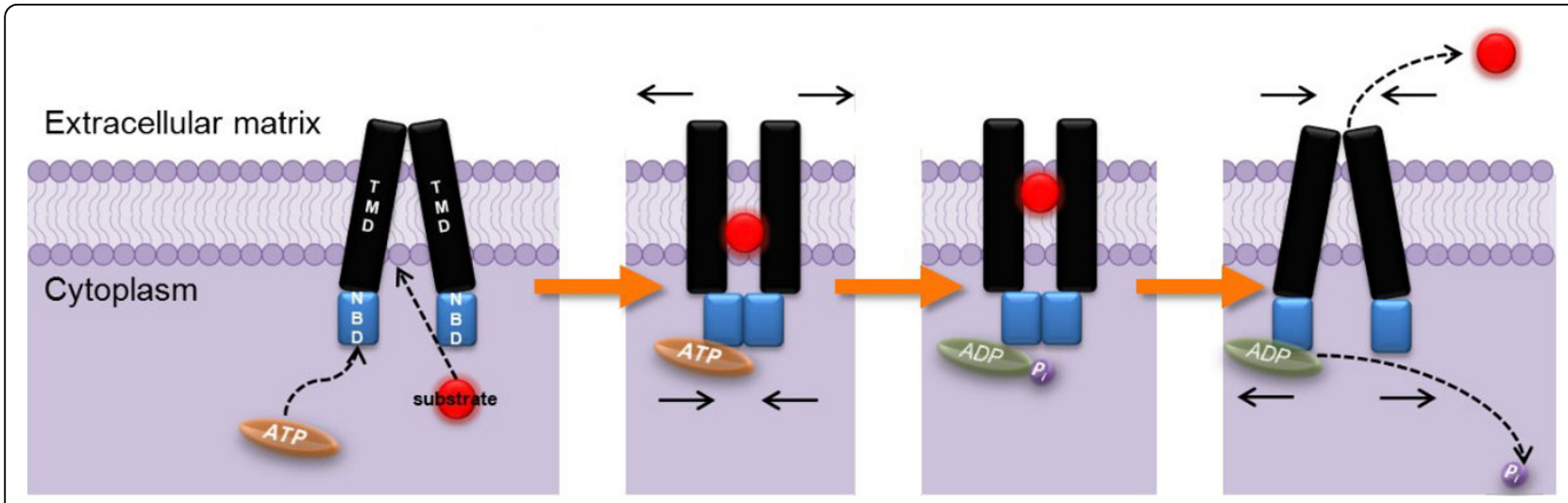

Figure 2 Proposed drug efflux mechanism for ABC transporters. Substrate and ATP bind to ATP transporters. After ATP hydrolysis, the substrate is effluxed out of the cell. Phosphate group is released and the substrate is then excreted to extracellular matrix.

tetrandrine with daunorubicin, etoposide and cytarabine demonstrated antileukaemic effects in 38 patients with acute myeloid leukaemia [38].

Matrine is a quinolizidine alkaloid from Sophora alopecuroides (Kudouzi). In resistant K562/DOX cell line, matrine (up to $50 \mu \mathrm{g} / \mathrm{mL}$, non-toxic) increased the intracellular accumulation of doxorubicin and induced its apoptotic effects [39]. Matrine enhanced the cytotoxicity of vincristine in resistant K562/VCR cell line [40]. It was proposed that matrine circumvented MDR by reducing Pgp expression [35].

Tetramethylpyrazine is an active alkaloid from Ligusticum chuangxiong (Chuanxiong) and a calcium channel blocker [41]. In Pgp-overexpressing resistant HL-60/ VCR cell line, tetramethylpyrazine significantly reversed MDR towards various drugs such as vincristine, duanorubicin and doxorubicin [42]. Tetramethylpyrazine reduced drug efflux (up to 50\%) in Pgp-overexpressing resistant MCF-7/DOX cell line [43]. When used together with $\beta$-elemene, tetramethylpyrazine exhibited stronger MDR reversal effects in resistant K562/DOX cell line [44]. Tetramethylpyrazine decreased Pgp expression in resistant HepG2/DOX cell line [45]. However, the reduction in Pgp expression was not universally observed. For instance, Pgp level was not altered despite MDR reversal in tetramethylpyrazine-treated K562/DOX cells [46].

Peimine (also known as verticine) is a cevanine type isosteroidal alkaloid from the bulbs of Fritillaria thunbergii (Zhebeimu) and other Fritillaria species [47,48]. In resistant K562/DOX and HL-60/DOX cell lines, peimine increased intracellular concentration of daunorubicin and reversed MDR probably through inhibition of Pgp expression [49].

Berbamine is a calcium channel blocker from Mahonia fortunei (Shidagonglao). In K562/DOX cell line, berbamine inhibited cell growth by inducing apoptosis in a dose-dependent manner and reduced Pgp expression thereby increasing the intracellular concentration of rhodamine-123 and doxorubicin [50,51]. In MCF-7/DOX cell line, O-(4-ethoxyl-butyl)-berbamine, a derivative of berbamine, reversed MDR by enhancing G2/M arrest and increasing the intracellular accumulation of doxorubicin [52].

\section{Active ingredients - saponins}

Ginsenosides are the major active components from Panax ginseng (Renshen). Ginsenosides are mainly triterpenoid dammarane derivatives. Several ginsenosides, namely $\operatorname{Rg}_{1}, \mathrm{Rg}_{3}, \mathrm{Re}, \mathrm{Rc}$ and $\mathrm{Rd}$ inhibited drug efflux [53]. A combination of purified saponins containing $R b_{1}, R b_{2}, R c, R d, R e$ and $R g_{1}$ reversed MDR whereas individual ginsenosides did not produce any effect [54]. Ginsenosides reversed MDR of several chemotherapeutic drugs such as homoharringtonine, cytarabine, doxorubicin and etoposide in K562/VCR and in a dose-dependent manner in K562/DOX [55]. Pgp expression decreased but bcl-2 expression remained the same [56]. $R b_{1}$ reversed MDR of harringtonolide and vincristine in K562/HHT and HL60/VCR cell lines respectively $[57,58]$.

Panax notoginseng (Sanqi) total saponins reversed MDR of doxorubicin in MCF-7/DOX and K562/VCR cell lines. The mechanism may be related to the decrease of Pgp expression [59,60].

\section{Active ingredients - flavonoids}

Quercetin is one of the most widely distributed flavonoids in natural products including Chinese medicinal herbs such as Sophora japonica (Huai). Quercetin inhibited the binding of heat shock factor at the MDR1 promoter, thereby decreasing MDR1 transcription and reducing Pgp expression [61]. Quercetin also inhibited the overexpression of Pgp mediated by arsenite [62]. In HL-60/DOX and K562/DOX cell lines, quercetin enhanced the anticancer sensitivity to daunorubicin and 
decreased Pgp expression [63,64]. MDR reversal effect of quercetin was probably mediated by its action on mitochondrial membrane potential and the induction of apoptosis. Furthermore, quercetin derivatives rather than quercetin itself reversed MDR [65]. Quercetin increased the sensitivity of Pgp-overexpressing KBV1 cell line towards vinblastine and paclitaxel in a dosedependent manner. Among many active flavonoids, quercetin was less potent than kaempferol but more effective than genistein and daidzein in reversing MDR. Genistein and daidzein had no effect on Pgp expression [66]. Although quercetin may be a potential MDR reversing agent, lethal drug-drug interaction between quercetin and digoxin has been reported. Quercetin $(40 \mathrm{mg} /$ $\mathrm{kg}$ ) elevated the peak blood concentration of digoxin and caused sudden death of tested animals [67].

Curcumin, the major component in Curcuma longa (Jianghuang), inhibited the transport activity of all three major ABC transporters, i.e. Pgp, MRP1 and ABCG2 [68]. Curcumin reversed MDR of doxorubicin or daunorubicin in K562/DOX cell line and decreased Pgp expression in a time-dependent manner [69]. Curcumin enhanced the sensitivity to vincristine by the inhibition of Pgp in SGC7901/VCR cell line [70]. Moreover, curcumin was useful in reversing MDR associated with a decrease in bcl-2 and survivin expression but an increase in caspase- 3 expression in COC1/DDP cell line [71]. The cytotoxicity of vincristine and paclitaxel were also partially restored by curcumin in resistant KBV20C cell line [72]. Curcumin derivatives reversed MDR by inhibiting Pgp efflux [72]. A chlorine substituent at the meta-or para-position on benzamide improved MDR reversal [72]. Bisdemethoxycurcumin modified from curcumin resulted in greater inhibition of Pgp expression [73]. Tetrahydrocurcumin, the major metabolite of curcumin, inhibited all three major ABC transporters [74]. Curcumin induced atypical and caspase-independent cell death in MDR cells [75]. In leukaemic cells collected from 78 childhood leukaemia patients, curcumin reduced Pgp expression [76]. A specialized nanoemulsion of curcumin is better than conventional solution form drugs in enhancing the efficiency of drug delivery into the cells, down-regulating Pgp expression, inhibiting the $\mathrm{NF} \kappa \mathrm{B}$ pathway and promoting apoptotic response $[68,77]$.

\section{Active ingredients - others}

Schizandrins, the active constituents of Schisandra chinensis (Wuweizi), were investigated for their MDR reversal effects. Schizandrin A was the most potent in reversing MDR by enhancing apoptosis and down-regulating Pgp and total protein kinase $\mathrm{C}$ expression. The crude extract of Schisandra chinensis reversed the resistance against vincristine in vivo [78]. Deoxyschizandrin and $\gamma$-schizandrin, among the nine dibenzo[a,c] cyclooctadiene lignans examined, enhanced intracellular drug concentration and induced cell cycle arrest at the G2/M phase when combined with sub-toxic dosages of doxorubicin [79]. Gomisin A, on the other hand, altered Pgp-substrate interaction by binding to Pgp simultaneously with substrates [80].

\section{Formulae - injections}

'Shengmai Injection', consisting of Panax ginseng and Ophiopogon japonicus (Maidong), down-regulated Pgp expression in peripheral blood lymphocyte membrane. When used together with oxaliplatin, 5-fluorouracil or folinic acid, the injection prolonged the survival rate of colon cancer patients [81]. The injection also enhanced the efficacy of tamoxifen and nifedipine in combination therapy [82].

Formulae - powders

'Shenghe Powder', consisting of Panax ginseng, Scorophularia ningpoensis (Xuanshen) and Atractylodes macrocephala (Baizhu), increased the intracellular concentration of vincristine in resistant SGC-7901/VCR cell line, possibly due to the induction of apoptosis and down-regulation of Pgp and bcl-2 expression [83].

'Modified Sanwubai Powder', consisting of herbs such as Croton tiglium (Badou), Platycodon grandiflorum (Jiegeng) and Fritillaria thunbergii, induced apoptosis in SGC-7901 cell line and down-regulated the gene expressions of p53, bcl-2, rasP21CD44 and Pgp [84].

\section{Formulae - others}

Three herbal extracts used to treat diseases other than cancer, namely Ams-11, Fw-13 and Tul-17, greatly enhanced the efficacy of vincristine both in vitro and in vivo and reversed MDR in a dose-dependent manner. Tul-17 inhibited Pgp expression [85].

Oil emulsion from Brucea javanica (Yadanzi) reversed MDR when used together with other chemotherapeutic drugs such as vincristine, doxorubicin, cisplatin, mitomycin C, 5-fluorouracil or etoposide, probably due to down-regulation of Pgp expression or inhibition of TOPO II or both $[86,87]$.

'Sangeng Mixture Decoction', consisting of Reynoutria japonica (Huzhang), Actinidia arguta (Mihouligen) and Geum aleppicum (Shuiyangmeigen), reversed MDR of doxorubicin via down-regulation of Pgp expression [88].

FFTLG, a formula containing Actinidia arguta, reversed MDR in K562/DOX cell line by increasing the intracellular doxorubicin concentration [89].

R1, consisting of Ligusticum chuanxiong, Curcuma longa and Millettia dielsiana (Jixueteng), enhanced the anticancer activities of doxorubicin in MCF-7/DOX via down-regulation of Pgp expression [90,91].

When tested with doxorubicin, 5-fluorouracil and epirubicin in HepG2/DOX cell line, Ganai-1, a commercial product, reversed MDR via down-regulation of Pgp expression [92]. Another commercial product, 
Tianfoshen, decreased Pgp expression in K562/DOX cell line and reversed MDR of doxorubicin [93]. An umbilical plaster used with 5-fluorouracil, mitomycin $\mathrm{C}$ or cisplatin reversed MDR via down-regulation of Pgp expression [94].

\section{MDR reversal not related to Pgp alteration Active ingredients - alkaloids}

Dauricine is a bisbenzylisoquinoline alkaloid isolated from the root of Menispermum dauricum (Bianfuge) as a calcium channel blocker. Dauricine reversed vincristine resistance in MCF-7/DOX cell line [95]. However, dauricine did not alter Pgp expression in K562/DOX cell line [96]. Moreover, dauricine enhanced the cytotoxic effects of doxorubicin in HL60/HAR cell line without increasing the intracellular concentration of doxorubicin or inhibiting Pgp overexpression [97].

Daurisoline, a structural analogue of dauricine, is also a calcium channel blocker isolated from the root of Menispermum dauricum. Both dauricine and daurisoline sensitized MCF-7/DOX cell line towards doxorubicin and vincristine in a dose-dependent manner [98]. The MDR reversal effects of dauricine and daurisoline are comparable to those of verapamil and both alkaloids do not cause cardiovascular adverse effect [99].

Active ingredients - saponins

20(S)-Ginsenoside $\mathrm{Rg}_{3}$, one of the active ginsenosides from Panax ginseng, restored the sensitivity of resistant KBV20 cell line to various anticancer drugs, including vincristine, doxorubicin, etoposide and colchicine in a time-and dose-dependent manner. This ginsenoside competitively inhibited the binding of substrate drugs to Pgp and its binding affinity to Pgp was remarkably higher than that of verapamil. In contrast to the dosedependent effects in vitro, 20(S)-ginsenoside $\mathrm{Rg}_{3}$ increased animal life span in an in vivo MDR model in a dose-independent manner [53].

\section{Active ingredients - flavonoids}

Paeonol is a weak calcium channel blocker isolated from the root of Paeonia suffruticosa (Mudan). In K562/DOX cell line, paeonol showed positive MDR reversal effect towards doxorubicin, daunorubicin, vincristine and vinblastine without modulating Pgp expression [100]. In parental K562 cells, paeonol induced apoptosis in a time-and dose-dependent manner [101].

\section{Formulae - injections}

'KLT Injection' consisting of the extract of Coix lacryma-jobi (Yiyi) enhanced the anticancer activities of paclitaxel and docetaxel and reversed MDR in a dosedependent manner [102].

\section{Formulae - others}

'Siwu Mixture', consisting of Paeonia lactiflora (Shaoyao), Rehmannia glutinosa (Dihuang), Angelica sinensis (Danggui) and Ligusticum chuanxiong, reversed doxorubicin MDR without altering Pgp expression in K562/DOX cell line [103].

\section{Other mechanisms \\ Active ingredients}

Pseudolaric acid B, a major active component of Pseudolarix kaempferi (Jinqiansong), reversed MDR in vitro and in vivo and induced apoptosis via cell cycle arrest at $\mathrm{G} 2 / \mathrm{M}$ phase. In either resistant cell line or nude mice model, pseudolaric acid B circumvented MDR associated with Pgp overexpression [104].

Salvinal, isolated from Salvia miltiorrhizae (Danshen), induced apoptosis and inhibited tubulin polymerization in various cancer cell lines, including the Pgp and MRPoverexpressing MDR cells [105].

A study on 22 compounds from CM herbs found that homoharringtonine, artesunate and bufalin from Cephalotaxus hainanensis (Hainancufei), Artemisia annua (Qinghao) and Bufo marinus, B. viridis (Chanchu) respectively exhibited active MDR modulation [106]. Moreover, other compounds such as jatrorrhizine, indirubin, rhynchophylline [107], arsenic trioxide [108,109], psoralen [110,111], oridonin [99,112], $\beta$-elemene $[113,114]$ also showed MDR reversal effects.

\section{Extracts}

Nine out of 20 extracts of Ganoderma species including G. lucidum (Lingzhi) were cytotoxic and induced apoptosis similar to etoposide and doxorubicin which are commonly used in chemotherapy. In etoposide-selected resistant cell line H69, G. lucidum extract increased the sensitivity to etoposide and doxorubicin significantly, possibly due to increased intracellular DNA fragmentation and caspases 3 and 9 activities [115]. Moreover, extracts of Glycyrrhiza glabra (Gancao), Hedyotis diffusa (Baihuasheshecao) and Rheum palmatum (Dahuang) reversed MDR by increasing the intracellular concentration of daunorubicin in SGC7901/VCR cell line [116]. Formulae

'Ganli Injection', consisting of matrine and tetramethylpyazine hydrochloride, reversed MDR by increasing the sensitivity of 5-fluorouracil and the intracellular concentration of doxorubicin in BEL-7402/5-FU cell line [117].

'Bushen Huayu Jiedu Formula', consisting of Cinnamomum cassia (Rougui), Psoralea corylifolia (Buguzhi) and Rheum palmatum, was tested in A549/DDP cell line and S180 tumour-bearing mice. In vitro, the formula significantly increased the intracellular concentration of cisplatin at high doses and inhibited the activity of calcium channel and LRP-56 expression at both high and low doses. In vivo, the formula improved the serum concentration, reduced the inflow and the release of $\mathrm{Ca}^{2+}$ and inhibited the LRP gene expression [118,119].

Four CM formulae, namely Glycyrrhiza glabra (GLYC), Hedyotis diffusa (OLEN), a formula consisting 
of 15 herbs including Cistanche deserticola (Roucongrong), Rabdosia rubescens (Donglingcao) and Zanthoxylum nitidum (Liangmianzhen) (SPES), and a formula consisting of eight herbs including Serenoa repens (Juyezhong), Scutellaria baicalensis (Huangqin), Panax ginseng and Glycyrrhiza glabra (PC-SPES) were cytotoxic to cancer cell lines in a dose-dependent manner. SPES, PC-SPES, OLEN decreased the $b c l-2$ gene expression and were pro-apoptotic, while GLYC was pronecrotic without altering the over-expression of bcl-2 in MDR cells. Furthermore, OLEN, SPES and PC-SPES exhibited similar pharmacological effects to etoposide and vincristine [120].

Many MDR reversing alkaloids are also calcium-channel blockers probably because of (1) their structural similarity and (2) inhibition of $\mathrm{ABC}$ transporters by the decrease in intracellular calcium concentration. Future research is warranted for potent MDR inhibitors without other pharmacological activities.

Over-expression of $\mathrm{ABC}$ transporters and enhanced drug efflux are the causes for MDR. Among the ABC transporters, Pgp is the most extensively studied for its role in MDR reversal effects. While other MDR reversal mechanisms remain unclear, Pgp inhibition is a criterion for further mechanistic study. This article summarises these proposed mechanisms (Additional file 1).

\section{Conclusion}

As some CM active ingredients reverse MDR by directly inhibiting growth and inducing apoptosis in cancer cells, the Pgp-inhibiting CM active ingredients may also be cytotoxic to cancer cells. Future studies should explore not only the MDR reversal effects but also the cytotoxic effects of various $\mathrm{CM}$ active ingredients.

\section{Additional material}

Additional file 1: Proposed mechanisms for MDR reversal by the tested Chinese medicinal herbs. The herbs are grouped into three categories, namely active ingredients, extracts and formulae. Pgp involvement is particularly considered: (+) inhibition on Pgp; (-) no effect on Pgp.

\begin{abstract}
Abbreviations
5-FU: 5-Flurouracil; ABC: Adenosine triphosphate-binding cassette; Ara-C: cytarabine; BCRP/ABCG2: Breast cancer resistance protein; CM: Chinese medicine; DDP: Cisplatin; DNR: Daunorubicin; DOC: Docetaxel; DOX: Doxorubicin; EPI: Epirubicin; FA: Folinic acid; HAR: Harringtonine; HHT: Harringtonolide; LOHP: Oxaliplatin; MDR: Multi-drug resistance; MMC: Mitomycin C; MRP1/ABCC1: Multidrug-resistance-associated protein 1; NFP: Nifedipine; Pgp/ABCB1: P-glycoprotein; PTX: Paclitaxel; TAM: Tamoxifen; VBL: Vinblastine; VCR: Vincristine; VP-16: Etoposide
\end{abstract}

\section{Acknowledgements}

The work was supported by a direct grant (2008.1.079) from The Chinese University of Hong Kong.

\section{Author details}

${ }^{1}$ School of Biomedical Sciences, Faculty of Medicine, The Chinese University of Hong Kong, Shatin, Hong Kong SAR, China. ${ }^{2}$ School of Pharmacy, Faculty of Medicine, The Chinese University of Hong Kong, Shatin, Hong Kong SAR, China.

\section{Authors' contributions}

SC and GL initiated the review and SC drafted the manuscript. GL and KT revised the manuscript. All authors read and approved the final version of the manuscript.

\section{Competing interests}

The authors declare that they have no competing interests.

Received: 4 March 2010 Accepted: 25 July 2010 Published: 25 July 2010

\section{References}

1. Meszaros A, Balogh G: Multiple Drug Resistance Lancaster, UK: Gazelle Distribution 2009.

2. Biedler $\mathrm{J}$, Riehm $\mathrm{H}$ : Cellular resistance to actinomycin D in Chinese hamster cells in vitro: cross-resistance, radioautographic, and cytogenetic studies. Cancer Res 1970, 30:1174-1184.

3. Gottesman MM: Mechanisms of cancer drug resistance. Annu Rev Med 2002, 53:615-617.

4. La Porta CAM: Drug resistance in melanoma: new perspectives. Curr Med Chem 2007, 14(4):387-91.

5. Watson JV: Introduction to Flow Cytometry Cambridge: Cambridge University Press 1991.

6. Szakacs G, Paterson JK, Ludwig JA, Booth-Genthe C, Gottesman MM: Targeting multidrug resistance in cancer. Nat Rev Drug Discov 2006, 5(3):219-234

7. Leonard GD, Fojo $T$, Bates SE: The role of $A B C$ transporters in clinical practice. Oncologist 2003, 8(5):411-424.

8. Juliano RL, Ling V: A surface glycoprotein modulating drug permeability in Chinese hamster ovary cell mutants. Biochim Biophys Acta Biomembranes 1976, 455(1):152-162.

9. Cordon-Cardo C, O'Brien JP, Boccia J, Casals D, Bertino JR, Melamed MR: Expression of the multidrug resistance gene product (P-glycoprotein) in human normal and tumor tissues. J Histochem Cytochem 1990, 38(9):1277-1287

10. Thiebaut F, Tsuruo T, Hamada H, Gotteman MM, Pastan I, Willingham MC: Cellular localization of the multidrug-resistance gene product $\mathrm{P}$ glycoprotein in normal human tissues. Proc Natl Acad Sci USA 1987, 84(21):7735-7738.

11. Aller SG, Yu J, Ward A, Weng Y, Chittaboina S, Zhuo R, Harrell PM, Trinh YT, Zhang Q, Urbatsch IL, Chang G: Structure of P-glycoprotein reveals a molecular basis for poly-specific drug binding. Science 2009, 323(5922):1718-1722.

12. Shapiro $A B$, Ling $V$ : Positively cooperative sites for drug transport by Pglycoprotein with distinct drug specificities. Eur J Biochem 1997, 250(1):130-137.

13. Cole SP, Bhardwaj G, Gerlach JH, Mackie JE, Grant CE, Almquist KC, Stewart AJ, Kurz EU, Duncan AM, Deeley RG: Overexpression of a transporter gene in a multidrug-resistant human lung cancer cell line. Science 1992, 258(5088):1650-1654.

14. Dean M, Hamon Y, Chimini G: The human ATP-binding cassette (ABC) transporter superfamily. J Lipid Res 2001, 42(7):1007-1017.

15. Liu F: Mechanisms of chemotherapeutic drug resistance in cancer therapy-a quick review. Taiwan J Obstet Gynecol 2009, 48(3):239-244.

16. Roelofsen $H$, Vos TA, Schippers IJ, Kuipers F, Koning H, Moshage $H_{\text {, }}$ Jansen PLM, Müller M: Increased levels of the multidrug resistance protein in lateral membranes of proliferating hepatocyte-derived cells. Gastroenterology 1997, 112(2):511-521.

17. Kruh GD, Gaughan KT, Godwin A, Chan A: Expression pattern of MRP in human tissues and adult solid tumor cell lines. J Natl Cancer Inst 1995, 87(16):1256-1258.

18. Hipfner DR, Deeley RG, Cole SPC: Structural, mechanistic and clinical aspects of MRP1. Biochim Biophys Acta-Biomembranes 1999, 1461(2):359-376. 
19. Doyle LA, Yang W, Abruzzo LV, Krogmann T, Gao Y, Rishi AK, Ross DD: A multidrug resistance transporter from human MCF-7 breast cancer cells. Proc Natl Acad Sci USA 1998, 95(26):15665-15670.

20. Allikmets $R$, Schriml LM, Hutchinson A, Romano-Spica V, Dean M: A human placenta-specific ATP-binding cassette gene (ABCP) on chromosome $4 q 22$ that is involved in multidrug resistance. Cancer Res 1998, 58(23):5337-5339.

21. Miyake K, Mickley L, Litman T, Zhan Z, Robey R, Cristensen B, Brangi M, Greenberger L, Dean M, Fojo T, Bates SE: Molecular cloning of cDNAs which are highly overexpressed in mitoxantrone-resistant cells: demonstration of homology to ABC transport genes. Cancer Res 1999 59(1):8-13.

22. Taylor EM: Efflux transporters and the blood-brain barrier New York: Nova Publishers 2005.

23. Maliepaard M, Scheffer GL, Faneyte IF, van Gastelen MA, Pijnenborg AC, Schinkel AH, van De Vijver MJ, Scheper RJ, Schellens JH: Subcellular localization and distribution of the breast cancer resistance protein transporter in normal human tissues. Cancer Res 2001, 61(8):3458-3464.

24. Sarkadi B, Homolya L, Szakács G, Váradi A: Human multidrug resistance $A B C B$ and $A B C G$ transporters: participation in a chemoimmunity defense system. Physiol Rev 2006, 86(4):1179-1236.

25. Litman T, Druley TE, Stein WD, Bates SE: From MDR to MXR: new understanding of multidrug resistance systems, their properties and clinical significance. Cell Mol Life Sci 2001, 58(7):931-959.

26. Twentyman PR: Cyclosporins as drug resistance modifiers. Biochem Pharmacol 1992, 43(1):109-117.

27. Tsuruo T, lida H, Tsukagoshi S, Sakurai Y: Overcoming of vincristine resistance in P388 leukemia in vivo and in vitro through enhanced cytotoxicity of vincristine and vinblastine by verapamil. Cancer Res 1981, 41(5):1967-1972

28. Toppmeyer D, Seidman AD, Pollak M, Russell C, Tkaczuk K, Verma S, Overmoyer B, Garg V, Ette E, Harding MW, Demetri GD: Safety and efficacy of the multidrug resistance inhibitor Incel (biricodar; VX-710) in combination with paclitaxel for advanced breast cancer refractory to paclitaxel. Clin Cancer Res 2002, 8(3):670-678.

29. Stewart A, Steiner J, Mellows G, Laguda B, Norris D, Bevan P: Phase I trial of XR9576 in healthy volunteers demonstrates modulation of $P$ glycoprotein in CD56+ lymphocytes after oral and intravenous administration. Clin Cancer Res 2000, 6(11):4186-4191.

30. Tian H, Pan QC: A comparative study on effect of two bisbenzylisoquinolines, tetrandrine and berbamine, on reversal of multidrug resistance. Yao Xue Xue Bao 1997, 32(4):245-250.

31. He QY, Meng FH, Zhang HQ: Reduction of doxorubicin resistance by tetrandrine and dauricine in harringtonine-resistant human leukemia (HL60) cells. Zhongguo Yao Li Xue Bao 1996, 17(2):179-181.

32. He QY, Jiang B, Zhang HQ, Xue SB: Reversal of doxorubicin resistance by tetrandrine in Chinese hamster ovary cell line. Zhongguo Yao Li Xue BaO 1992, 13(5):416-419.

33. Choi SU, Park SH, Kim KH, Choi EJ, Kim S, Park WK, Zhang YH, Kim HS, Jung NP, Lee CO: The bisbenzylisoquinoline alkaloids, tetrandine and fangchinoline, enhance the cytotoxicity of multidrug resistance-related drugs via modulation of P-glycoprotein. Anticancer Drugs 1998, 9(3):255-261

34. Sun AX, Ye ZG, Li CY, Xue BY, Li LF, Cao XF, Yang Q, Dai BQ: Synergistic anticancer effects of tetrandrine combined with doxorubicin or vincristine in vitro. Acta Pharmacol Sin 1999, 20(1):69-73.

35. Li GH, Pan CY, Sun FJ, Wang XR, Yin GP: Reversal effect of 4 alkaloids on apoptosis of being obtained multi-drug resistance to tumour cell. Chin Trad Patent Medicine 2006, 28(7):1001-1004.

36. Fu LW, Zhang YM, Liang YJ, Yang XP, Pan QC: The multidrug resistance of tumour cells was reversed by tetrandrine in vitro and in xenografts derived from human breast adenocarcinoma MCF-7/adr cells. Eur J Cancer 2002, 38(3):418-426.

37. Wang F, Wang L, Yang J, Nomura M, Miyamoto K: Reversal of Pglycoprotein-dependent resistance to vinblastine by newly synthesized bisbenzylisoquinoline alkaloids in mouse leukemia P388 cells. Biol Pharm Bull 2005, 28(10):1979-1982

38. Xu WL, Shen HL, Ao ZF, Chen BA, Xia W, Gao F, Zhang YN: Combination of tetrandrine as a potential-reversing agent with daunorubicin, etoposide and cytarabine for the treatment of refractory and relapsed acute myelogenous leukemia. Leuk Res 2006, 30(4):407-413.
39. Ding YF, Xie X, Zhao JY, Yang PM: Reversal of adriamycin resistance by matrine in leukemia multidrug resistance cell line K562/ADM. J Dalian Med Univ 2004, 26(4):256-258, 279.

40. Li XF, Zhang SZ, Zheng S: Cellular biological effects of matrine on K562 and K562/Vin cells. Chin J Pathophysiol 2002, 18(10):1233-1237.

41. Tan Z: Neural protection by naturopathic compounds - an example of tetramethylpyrazine from retina to brain. J Ocul Biol Dis Infor 2009, 2(2):57-64.

42. Yang $L$, Yang PD, Liang R, Yuan YC, Tian Q: Study on reversal of multidrug resistance in leukemia by tetramethylphylpyrazine combining with cyclosporin A. Chin J Cancer 2000, 19(4):304-306.

43. Zhou C, Shen P, Cheng Y: Quantitative study of the drug efflux kinetics from sensitive and MDR human breast cancer cells. Biochim Biophys Acta - Gen Subjects 2007, 1770(7):1011-1020.

44. Hao LH, Zhao JY, Yang PM: The Studies of Tetramethylpyrazine in Combination with $\beta$-Elemene on Induction of the Apoptosis and the Reversal of Multidrug Resistance in K562/ADM Cells Line. Chin J Clin Oncol 2005, 32(1):25-28, 33

45. Ji YB, Ji CF, Zou X, Gao SY: Study on the effects of two kinds of cactus polysaccharide on erythrocyte membrane protein and fluidity of the lipid in S180 mice. Zhongguo Zhong Yao Za Zhi 2004, 29(10):967-970.

46. Li JH, Yang PM: Study on ligustrazine in reversing multidrug resistance of K562/ADM cell. Mod J Integr Chin Tradit West Med 2001, 10(15):1405-1407.

47. Li SL, Chan SW, Li P, Lin G, Zhou GH, Ren YJ, Chiu FC: Pre-column derivatization and gas chromatographic determination of alkaloids in bulbs of Fritillaria. J Chromatogr A 1999, 859(2):183-192.

48. Lin G, Li SL, Li P, Chan SW: Chromatographic analysis of Fritillaria isosteroidal alkaloids, the active ingredients of Beimu, the antitussive traditional Chinese medicinal herb. J Chromatogr A 2001, 935(12):321-338.

49. Hu HW, Zheng HX, Qi J, Hou L, Zuo MH, Chen XY, Sun YL, Xu YF, Shao XF, Yang CZ: Study of reversing multi-drug resistant by Peimine. Chin J Hem 1999, 20(12):650-651

50. Dong Q, Zheng S, Xu R, Lu Q, He L: Study on effect of berbamine on multidrug resistance leukemia K562/Adr cells. Chin J Integr Tradit West Med 2004, 24(9):820-822.

51. Han Y, Yuan J, Shi Y, Zhu Y, Wu S: Reversal effect of berbamine on multidrug resistance of K562/DOX cells and its mechanism. J Exp Hematol 2003, 11(6):604-608.

52. Cheng YH, Qi J, Xiong DS, Liu JW, Qi SL, Pan B, Yang CZ, Zhu HF: Reversal of multidrug resistance in drug-resistant human breast cancer cell line MCF-7/ADR by calmodulin antagonist O-(4-ethoxyl-butyl)-berbamine. Zhongguo Yi Xue Ke Xue Yuan Xue Bao 2006, 28(2):164-168.

53. Kim SW, Kwon HY, Chi DW, Shim JH, Park JD, Lee YH, Pyo S, Rhee DK: Reversal of P-glycoprotein-mediated multidrug resistance by ginsenoside Rg3. Biochem Pharmacol 2003, 65(1):75-82.

54. Park JD, Kim DS, Kwon HY, Son SK, Lee YH, Baek NI, Kim SI, Rhee DK: Effects of ginseng saponin on modulation of multidrug resistance. Arch Pharm Res 1996, 19(3):213-218.

55. Gao RL, Lin XJ, Qian XD, Chen XH, Niu YP: Effect of ginsenosides and panaxatriol extracted from ginseng on inhibition of proliferation, inducing apoptosis and cytotoxic drug sensitivity in leukemic cells. $J$ Chin Med Res 2004, 4(2):97-99.

56. Wang Li: Reversing drug resistance of human erythroleukemia cell line K562/DOX on DOX by total saponings Panax ginseng. J Chongqing Med Univ 2003, 28(4):424-427, 435.

57. Shi XK, Zhang YJ, Zhao CJ: The reverse effects of ginseng saponin Rb1 on multidrug resistance of human leukemic cell line K562/HHT in vitro. Acta Acad Med Militaris Tertiae 1999, 21(11):825-827.

58. Li Y, Wang ZZ, Yu TF: In vitro study on the reversal of multidrug resistance (MDR) in HL60/VCR cell line with ginsenoside - Rb1. J Radioimmunol 2005, 18(5):362-365.

59. Liu LL, Liu YE, Fang GT: Reversal effect of Panax notoginseng saponins on multidrug resistance breast cancer cell MCF/ADM. Lishizhen Med Materia Med Res 2008, 19(4):954-956.

60. Si YQ, Tien TD: The multidrug resistant reversing effect of total Panax notoginseng saponins studied in K562/VCR cell line. Chin J Tradit Med Sci Technol 2005, 12(5):292-294.

61. Kim SH, Yeo GS, Lim YS, Kang CD, Kim CM, Chung BS: Suppression of multidrug resistance via inhibition of heat shock factor by quercetin in MDR cells. Exp Mol Med 1998, 30(2):87-92. 
62. Kioka N, Hosokawa N, Komano T, Hirayoshi K, Nagata K, Ueda K: Quercetin, a bioflavonoid, inhibits the increase of human multidrug resistance gene (MDR1) expression caused by arsenite. FEBS Lett 1992, 301(3):307-309.

63. Cai X, Chen FY, Han JY, Gu CH, Zhong H, Teng Y, Ouyang RR: Reversal of multidrug resistance of $\mathrm{HL}-60$ adriamycin resistant leukemia cell line by quercetin and its mechanisms. Chin J Oncol 2005, 27(6):326-329.

64. Cai X, Chen FY, Han JY, Gu CH, Zhong H, Ouyang RR: Restorative effect of quercetin on subcellular distribution of daunorubicin in multidrug resistant leukemia cell lines K562/ADM and HL-60/ADM. Chin J Cancer 2004, 23(12):1611-1615.

65. Kothan S, Dechsupa S, Leger G, Moretti JL, Vergote J, Mankhetkorn S: Spontaneous mitochondrial membrane potential change during apoptotic induction by quercetin in $\mathrm{K} 562$ and K562/adr cells. Can J Physiol Pharm 2004, 82(12):1084-1090.

66. Limtrakul P, Khantamat O, Pintha K: Inhibition of P-glycoprotein function and expression by kaempferol and quercetin. J Chemother 2005, 17(1):86-95.

67. Wang Y, Chao PL, Hsiu SL, Wen K, Hou Y: Lethal quercetin-digoxin interaction in pigs. Life Sci 2004, 74(10):1191-1197.

68. Ganta S, Amiji M: Coadministration of paclitaxel and curcumin in nanoemulsion formulations To overcome multidrug resistance in tumor cells. Mol Pharm 2009, 6(3):928-939.

69. Chang HY, Pan KL, Ma FC, Jiao XY, Zhu HF, Liu JH, Huang Y, Cao YH: The study on reversing mechanism of multidrug resistance of K562/DOX cell line by curcumin and erythromycin. Chin J Hem 2006, 27(4):254-258.

70. Tang XQ, Bi H, Feng JQ, Cao JG: Effect of curcumin on multidrug resistance in resistant human gastric carcinoma cell line SGC7901/VCR. Acta Pharmacol Sin 2005, 26(8):1009-1016.

71. Ying HC, Zhang SL, LV J: Drug-resistant reversing effect of curcumin on COC1/DDP and its mechanism. J Mod Oncol 2007, 15(5):604-607.

72. Um Y, Cho S, Woo HB, Kim YK, Kim H, Ham J, Kim SN, Ahn CM, Lee S: Synthesis of curcumin mimics with multidrug resistance reversal activities. Bioorg Med Chem 2008, 16(7):3608-3615.

73. Limtrakul P, Anuchapreeda S, Buddhasukh D: Modulation of human multidrug-resistance MDR-1 gene by natural curcuminoids. BMC Cancer $2004,4: 13$

74. Limtrakul P, Chearwae W, Shukla S, Phisalphong C, Ambudkar SV: Modulation of function of three $A B C$ drug transporters, P-glycoprotein $(A B C B 1)$, mitoxantrone resistance protein $(A B C G 2)$ and multidrug resistance protein $1(A B C C 1)$ by tetrahydrocurcumin, a major metabolite of curcumin. Mol Cell Biochem 2007, 296(1-2):85-95.

75. Piwocka K, Bielak-Mijewska A Sikora E: Curcumin induces caspase-3independent apoptosis in human multidrug-resistant cells. Ann N Y Acad Sci 2002, 973:250-254.

76. Anuchapreeda S, Thanarattanakorn P, Sittipreechacharn S, Tima S, Chanarat $P$, Limtrakul $P$ : Inhibitory effect of curcumin on MDR1 gene expression in patient leukemic cells. Arch Pharm Res 2006, 29(10):866-873.

77. Choi BH, Kim CG, Lim Y, Shin SY, Lee YH: Curcumin down-regulates the multidrug-resistance mdr1b gene by inhibiting the PI3K/Akt/NF kappa B pathway. Cancer Lett 2008, 259(1):111-118.

78. Huang M, Jin J, Sun H, Liu GT: Reversal of P-glycoprotein-mediated multidrug resistance of cancer cells by five schizandrins isolated from the Chinese herb Fructus Schizandrae. Cancer Chemother Pharmacol 2008, 62(6):1015-1026.

79. Slaninová I, Brezinová L, Koubíková L, Slanina J: Dibenzocyclooctadiene lignans overcome drug resistance in lung cancer cells-study of structure-activity relationship. Toxicol In Vitro 2009, 23(6):1047-1054.

80. Wan CK, Zhu GY, Shen XL, Chattopadhyay A, Dey S, Fong WF: Gomisin A alters substrate interaction and reverses P-glycoprotein-mediated multidrug resistance in HepG2-DR cells. Biochem Pharmacol 2006, 72(7):824-837.

81. Cao $C M$, Ding XD, Wang XH, Liu P: Clinical study of shengmai injection in its reversing MDR effect in late phase colon carcinoma patients. Shandong J Tradit Chin Med 2005, 24(9):529-532.

82. Lin SY, Qin ZQ, Xu YF, Wu LC, Liu LM: Significance of combination shenmal injection, tamoxifen and nifedipine in treatment stage IV nonsmall cell lung cancer. Chin J Cancer Prev Treat 2002, 9(4):454-455.

83. Wang J, Xia Y, Wang H, Hou Z: Chinese herbs of Shenghe powder reverse multidrug resistance of gastric carcinoma SGC-7901. Integr Cancer Ther 2007, 6(4):400-404.
84. Xu L, Wang MY, Xu DQ, Zhou CX: Experimental study on modified "Sanwubai Powder" in affecting multi-drug resistance gene expression of tumor. Shanghai J Tradit Chin Med 2005, 39(8):59-60.

85. Qu Y, Liu SQ, Zhang XB, Bai SH, Tang XY, Zhang TH, Liu BL: Reversal of Pglycoprotein mediated multidrug resistance by traditional Chinese medicines. Nat Prod Res Dev 2006, 18(6):932-936.

86. Yu LF, Wu YL, Zhang YP: Reversal of drug resistance in the vincristineresistant human gastric cancer cell lines MKN28/VCR by emulsion of seminal oil of Brucea Javanica. World Chin J Digestol 2001, 9(4):376-378.

87. Tang T, Meng LH, Chen LJ, Ding J: Reversal of multidrug resistance and inhibition of DNA topoisomerase II by emulsion of seed oil of Brucea Javanica. Chin Pharmacol Bull 2001, 17(5):539-542.

88. Feng ZQ, Guo Y, Zhu NX, Lu QH, Shen MH, Wu LC, Wang ZS: The experiment of SANGENG mixture decoction on reversing multidrug resistance. Bull Chin Cancer 2003, 12(6):370-371.

89. Guo Y, Xie CS, Feng ZQ: The study of effects on accumulation and efflux of intracellular adrimycine with FFTLG for multidrug resistant cell lines K562/ADR and K562/VCR in vitro. Chin J Mod Appl Pharm 2002, 19(4):268-272.

90. Lin GF: Current situation in studying the reversing effect in multidrugresistant in cancer cells by TCM. China Pharm 2007, 16(10):63-64.

91. Chen XY, Liu JT: Study on tumor cells' multidrug resistance and its reversion by Chinese herbs. J Chin Integr Med 2003, 1(3):221-225.

92. Li Q, Liu ZJ, Zhang J, Shi YJ, Gong JP: The effects of GanAi-1 on the reversal of multidrug resistance in hepcatocellular carcinoma. J Dig Surg 2006, 5(1):70-73

93. Yang GW, Dang Q, Li XM: Reversal effects and mechanism study of Tianfoshen on drug resistance of human erythrocyte leukaemic cell strain K562/ADM. Mod J Integr Tradit Chin West Med 2002, 11(19):1865-1867.

94. Lu WP, Suen GZ: Effect of Zeng Xio umbilical plaster in MDR malignant ascites patient. J Chin Physician 2006, 34(2):48-50.

95. Ye ZG, Wang JH, Sun AX, Liang AH, Xue BY, Li CY, Wang L: Potentiation of vincristine-induced apoptosis by tetrandrine, neferine and dauricine in the human mammary MCF-7 multidrug-resistant cells. Yao Xue Xue Bao 2001, 36(2):96-99.

96. Li JH, Qin FQ, Yang PM: Reversal of multidrug resistance in human K562/ ADM cell line by dauricine. J Dalian Med Univ 2002, 24(2):94-96.

97. Liu ZM, Xu ZP, Shou LH: Progress of reversing multi-drug resistant in TCM. Chin J Integr Trad West Med 1999, 19(12):757-759.

98. Tian F, Pan QC: Comparative study for reversing multi-drug resistant in dauricine and daurisoline. Chin J Cancer 1996, 15(6):410-414.

99. Song XR, Hou SX: Research progress in reversing multi-drug resistant in TCM. Zhongguo Zhong Yao Za Zhi 2005, 30(16):1300-1304.

100. Sun HJ, Wang $X Q$, Yu LM, Zhao JY, Yang PM: The study of paeonol for MDR's reverse action. Prog of Anat Sci 2000, 6(1):59-62.

101. Sun GP, Wang H, Shen YX, Zhai ZM, Wei W, Xu SY: Study on effects of paeonol in inhibiting growth of K562 and inducing its apoptosis. Chin Pharmacol Bull 2004, 20(5):550-552.

102. Dong QH, Zheng S, Lu QH: Study on the effect of Kanglaite injection on MDR human leukemia cell lines. J Pract Oncol 2002, 17(1):24-26.

103. Xia $L$, Shen P: Studies on the effects of Siwu Mixture on reversing multidrug resistance of human erythrocyte leukemic cell line K562/ADM. Zhongguo Zhong Yao Za Zhi 2004, 29(8):792-795.

104. Wong VK, Chiu P, Chung SS, Chow LM, Zhao YZ, Yang BB, Ko BC: Pseudolaric acid $B$, a novel microtubule-destabilizing agent that circumvents multidrug resistance phenotype and exhibits antitumor activity in vivo. Clin Cancer Res 2005, 11(16):6002-6011.

105. Chang JY, Chang CY, Kuo CC, Chen LT, Wein YS, Kuo YH: Salvinal, a novel microtubule inhibitor isolated from Salvia miltiorrhizae bunge (Danshen), with antimitotic activity in multidrug-sensitive and -resistant human tumor cells. Mol Pharmacol 2004, 65(1):77-84.

106. Efferth T, Davey M, Olbrich A, Rücker G, Gebhart E, Davey R: Activity of drugs from traditional Chinese medicine toward sensitive and MDR1-or MRP1-overexpressing multidrug-resistant human CCRF-CEM leukemia cells. Blood Cells Mol Dis 2002, 28(2):160-168.

107. Zhang HZ, Yang L, Ren LM, Liu SM: Drug screening for reversal of multidrug resistance in tumor cell from Chinese drug active compounds in vitro. J North China Coal Med Coll 2003, 5(3):265-267.

108. Li JW: Study progress in TCM for the multidrug-resistant reversing effect. Hebei J TCM 2007, 29(6):557-560. 
109. Yang SL, Pang J, Chen HP: Research progress in reversing MDR by Chinese medicine. J Hepatobiliary Surg 2008, 16(6):477-479.

110. Chang $X H$, Xiang $Y$, Huang SL: Review on revering multidrug resistance with Chinese herbs leukemia. J Bran Camp First Mil Med Univ 2004, 27(2):200-203.

111. Bao WL: Study progress in MDR reversal effect in Chinese medicine. Lishizhen Med Mater Med Res 2008, 19(12):2905-2907.

112. Suen JL, Li CJ, Liang F, Liu JX: Thoughts in using TCM to reverse multidrug resistance. Chin Arch Trad Chin Med 2006, 24(4):736-737.

113. Liu LS, Tien JH, Shi ZM: Advances in research on reversing multidrug resistance of tumour. Trad Chin Med Res 2003, 16(1):43-45.

114. Ma Q, Zhang ZS: Research review in reversing MDR by TCM. J Hunan Coll TCM 2002, 22(4):70-72.

115. Sadava D, Still DW, Mudry RR, Kane SE: Effect of ganoderma on drugsensitive and multidrug-resistant small-cell lung carcinoma cells. Cancer Lett 2009, 277(2):182-189.

116. Gu YL, Chu HH, Bu P: Experimental study for reversing MDR in gastric cancer by several TCM. Trad Chin Drug Res Clin Pharmacol 2007, 18(2):114-116.

117. Gu W, Zhai XF, Zhang YN, Ling CQ: In vitro study of Ganli injection on reversing acquired multidrug resistance of human hepatocellular carcinoma. Chin Trad Herbal Drugs 2007, 38(6):871-874.

118. Cao Y, Xia Q, Meng H, Zhong A: Pharmacological effects of serum containing chinese medicine bushen huayu jiedu compound recipe in lung cancer drug-resistance cells. Chin J Integr Med 2008, 14(1):46-50.

119. Cao Y, Zhang D, Zheng GJ, Yang Y, Zhang J: Study on drug resistance reversion and mechanism of bushen huayu jiedu formula in lung cancer cells of drug resistance. Shandong J Trad Chin Med 2004, 23(2):100-104.

120. Sadava D, Ahn J, Zhan M, Pang ML, Ding J, Kane SE: Effects of four Chinese herbal extracts on drug-sensitive and multidrug-resistant smallcell lung carcinoma cells. Cancer Chemother Pharmacol 2002, 49(4):261-266

doi:10.1186/1749-8546-5-26

Cite this article as: Chai et al: Circumvention of multi-drug resistance of cancer cells by Chinese herbal medicines. Chinese Medicine 2010 5:26.

\section{Submit your next manuscript to BioMed Central and take full advantage of:}

- Convenient online submission

- Thorough peer review

- No space constraints or color figure charges

- Immediate publication on acceptance

- Inclusion in PubMed, CAS, Scopus and Google Scholar

- Research which is freely available for redistribution 